\title{
MedEClasses Advanced Pediatric Endocrinology, Volumes I and II: Anurag Bajpai (ed)
}

\author{
Published by MedEClasses Publications, Kanpur, Uttar Pradesh, India; First Edition; 2021; ASIN: \\ B094PSMC29 \& B097RNRB4Z; Pages: 326 \& 340; Price: ₹ 3000/- \& 3000/-
}

\author{
P. Raghupathy ${ }^{1}$
}

Received: 28 October 2021 / Accepted: 3 November 2021 / Published online: 22 January 2022 (c) Dr. K C Chaudhuri Foundation 2021

MedEClasses Advanced Pediatric Endocrinology (in two volumes) is rightly yet another remarkable, resourceful tool from Dr Anurag Bajpai and his colleagues to help both beginners and the experienced alike, for understanding easily and gaining extensive in-depth knowledge of Pediatric Endocrinology. This is indeed a valuable addition to the voluminous repository of educational material produced constantly for nearly a decade or longer by Dr Bajpai with his enormous zeal to motivate the younger generation of pediatricians and to increase their awareness by presenting to them the complex field of pediatric endocrinology in simple terms. The numerous simplified line diagrams and cartoons in each chapter are an ample testimony to this fact.

The fundamentals as well as the applied aspects involved have been explained clearly, while unravelling the basis of clinical features, outlining the practical approach to relevant diagnostic investigations and treatment. Clinical vignettes pertaining to the various topics have also been presented conveniently to serve as practical guidelines in managing the cases. Endocrine crosstalks are highly innovative, as these bring home the fact that many of the hormones are interconnected in their action.

The inclusion of a chapter on Endocrine Research is also a welcome feature to instill the idea of simultaneous research while working in this field. Clear steps of how to postulate a hypothesis, frame a research question in one's mind, plan the study, evaluate the data with appropriate statistical analysis are all laid out in detail. A chapter of this kind is quite unusual in a specialty textbook.

Nevertheless, Pediatric postgraduates and trainees in fellowship courses will be eagerly searching the book for chapters on 'Approach to Short Stature' and 'Disorders of Sex Differentiation.' A separate section on normal and abnormal puberty in boys and girls, is clearly missing, although only a few brief explanations have been given in the chapters on Ovarian and Testicular disorders. One may need to refer to the other publications by Dr Bajpai for these topics.

A detailed Index at the end will also be useful in quickly finding the searched context for the impatient trainee. Knowing Dr Bajpai and his great enthusiasm, I am sure he will be already planning for the next edition with the desired modifications.

I have no hesitation in highly recommending this book to those undergoing pediatric endocrine training currently or to the seniors who wish to update to current knowledge.

Publisher's Note Springer Nature remains neutral with regard to jurisdictional claims in published maps and institutional affiliations.

P. Raghupathy

drp.raghupathy@gmail.com

1 Department of Pediatric \& Adolescent Endocrinology, Indira Gandhi Institute of Child Health, No. 39, 6th Cross, 35th Main Road, K.A.S. Officers' Colony, B.T.M. Layout 2nd Stage, Bangalore, Karnataka 560 068, India 